\title{
Using Serious Games to Correct French Dictations: Proposal for a New Unity3D/NooJ Connector
}

\author{
Ikram Bououd and Rania Fafi \\ Higher Institute of Management of Gabes \\ ikram.bououd@gmail.com,ranyafafi93@gmail.com
}

\begin{abstract}
The remarkable growth in serious games use has gradually pushed them to be present in every single domain. However, in language learning we did not find any reliable games developed for dictation exercises, commonly used for the teaching of French. This involves natural language processing in the form of an interactive game that can automatically generate corrections and assess game users. In order to fill this research gap, we propose to take advantage of the assets provided by the NooJ platform and develop a game combining NooJ and the 3D game platform Unity3D.
\end{abstract}

\section{Introduction}

Serious Games (SG) constitute a new educational frame. This oxymoron represents a powerful means to spread serious content in an entertaining way (Abt, 1970). SG are experiencing a huge increase within our societies and invading every single domain: healthcare, the military, education, advertisement, coaching, etc. (Alvarez and Rostaing, 2014). The important use of these games has gradually put them as an important research area, especially when SG are dealing with an attractive and crucial topic such as education and language learning.

Developing a serious game for language learning, in particular for a dictation exercise, led us to make use of different resources from Natural Language Processing (NLP). The main challenge was to create a successful connection between the game platform, here Unity3D, and the NLP platform, here NooJ. To the best of our knowledge such a connection between these two platforms has never been proposed.

This game allows better interactivity along with automatic correction of a French dictation exercise for the language learner. This will offer added value to language learning and can make the gamer more sophisticated.

\section{Serious Games}

Alvarez defines SG as "computer applications having as original intention to combine both serious aspects (serious), with fun aspects from video games (game). Such an association is achieved by providing a learning scenario corresponding, from a programming point of view, to implement a decor (sound and graphics), story and suitable rules; therefore it moves away from restricting the game to entertainment" (Alvarez and Rostaing, 2014).

Indeed, SG are entertaining games for educational purpose. The main objective is to exploit the entertaining aspect of video games to facilitate learning concepts, traditionally taught through conventional teaching methods. The range of usage areas of SG is very wide such as scientific exploration, medicine and education. More precisely, the educational aspect of SG is one of their greatest assets. Indeed, SG are promoting and opening new horizons for active learning and provide a learningby-doing experience. Thanks to their graphics and design, SG are well accepted among the young generation since they succeed in keeping them concentrated on their tasks and engage them in the learning process (Berta et al., 2016).

The learning part of the game is the most important. Many discussions have explored reward systems as ways to motivate student participation and practice. However, when people began to look at the potential of games for student engagement, they found that the games fit well within the theories of learning.

This approach can potentially help students master the learning process. The use of online gaming integrated into education has a positive impact on student learning thanks to their graphics and design, since SG keep them concentrated on their tasks and

Proceedings of the Linguistic Resources for Automatic Natural Language Generation Workshop, pages 4952, Santiago de Compostela, Spain, September 4, 2017. (C) 2017 Association for Computational Linguistics 


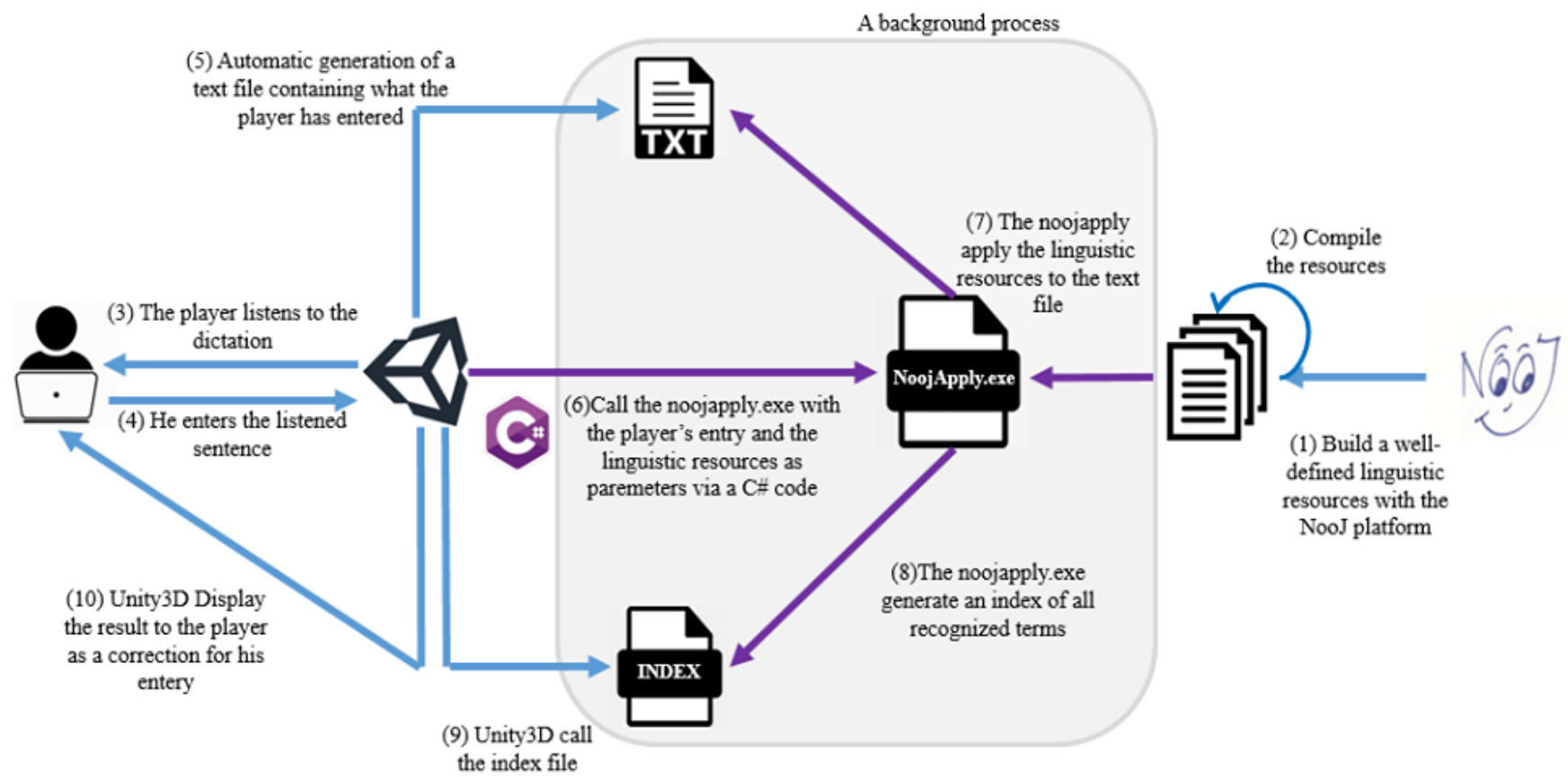

Figure 1: Approach overview

engage them in the learning process (Berta et al., 2016).

\section{Learning languages and games}

Learning languages is crucial and requires several competencies: listening, speaking, pronunciation, reading, writing, as well as dictation, which combines listening and writing. Language learning requires concentration and endurance, which are hard to maintain for a long periods of time. Consequently, learners will quickly feel bored, lose concentration and then neglect the engagement to learn.

Games overcome this point by integrating heavy learning materials in a playful way and make learning processing smooth and encouraging (Graesser, 2016). The literature of serious games provides several games for language learning such as English pronunciation (Trooster et al., 2016) or German learning (Alyaz et al., 2017). Some games are proposed for children with Down syndrome (Simao et al., 2016) to learn phonetics, etc. Existing games did not provide an automatic language processing of users' input and did not correct their responses with a customized way. Indeed, they need to write down their responses and compare them later with the right responses provided by the game (Alyaz et al., 2017).

We decided to take advantage of the NooJ platform to create an automatic language-learning process that reinforces dictation and writing skills. To the best of our knowledge, a game dealing with interactive correction of dictation has not yet been proposed.

\section{SG Proposal based on NLP}

\subsection{NooJ/Unity connection: Approach over- view}

Building the connection between Unity3D and NooJ was the first step we took (Figure 1). Dictation is designed to build various language skills listening, pronunciation, spelling and writing words correctly from individual letters. First of all, we concentrated on building new NooJ resources (dictionaries and grammars) to recognize certain word forms from their components (prefixes, affixes and suffixes) (Silberztein, 2003). This task allows us to determine whether each word entered by the player is written correctly or not. 
But this is not enough for dictation correction or detecting the incorrect agreement between subject and verb or any mistaken combinations in the sentence. So we have resorted to building another syntactic grammar that describes full sentences, and decides whether the formulated sentences are consistent in terms of agreement, gender, number and person or not.

Secondly, after building the linguistic resources, we moved on to compile them to be used as parameters in the command-line noojapply within NooJ (Silberztein and Tutin, 2005).

When the player listens to the provided dictation, he/she enters his/her response in a text box inside the game. After sending his/her response, Unity3D (using C\# code) will divide the entered sentence into separate words in a new generated text file; each of these words would be a NooJ platform entry to be processed.

Noojapply is then called from the $\mathrm{C} \#$ code inside the game. At this point, we are able to connect the entry of the player, saved automatically to a text file, to the compiled lexical resources, the parameters that noojapply needs.

NooJ then applies the provided linguistic resources word by word in a loop to detect eventual misspelled words and sends the index of each word to Unity3D to be saved in an index file. And then it will apply syntactic resources to detect any wrong agreement within the sentence.

The coherent answer is the one that matches one of the grammars' paths. This index file is what we use to display the correction to the player. The final result is displayed to the player as a correction to his/her mistakes.

\subsection{Experimentation}

The player explores the terrain searching for a sound source, once he/she finds it; he/she will be able to control the listening with a keyboard key.

When the player finishes listening to the French dictation, a new panel appears, giving him a place to write the sentence heard (Figure 2).

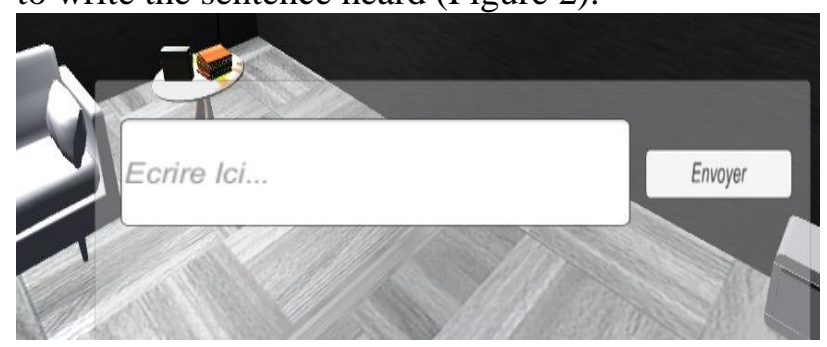

Figure 2: The entry field

After writing the sentence heard and by clicking on the "Envoyer" button (Figure 3) the correction process begins in the game's background.

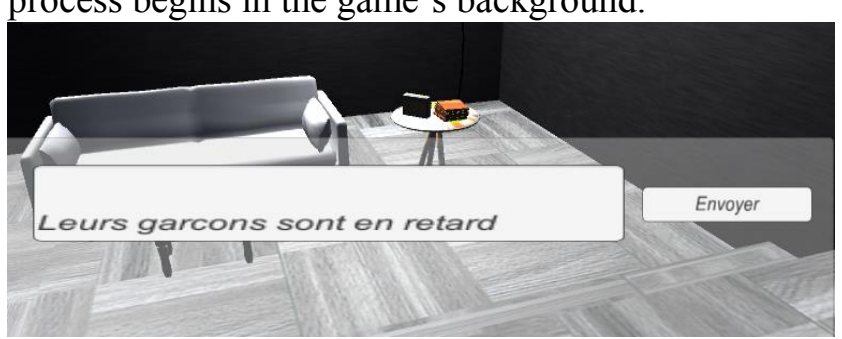

Figure 3: The entry field after listening to the message

Some examples of detected mistakes and their corrections can be seen in Figure 4 and Figure 5.

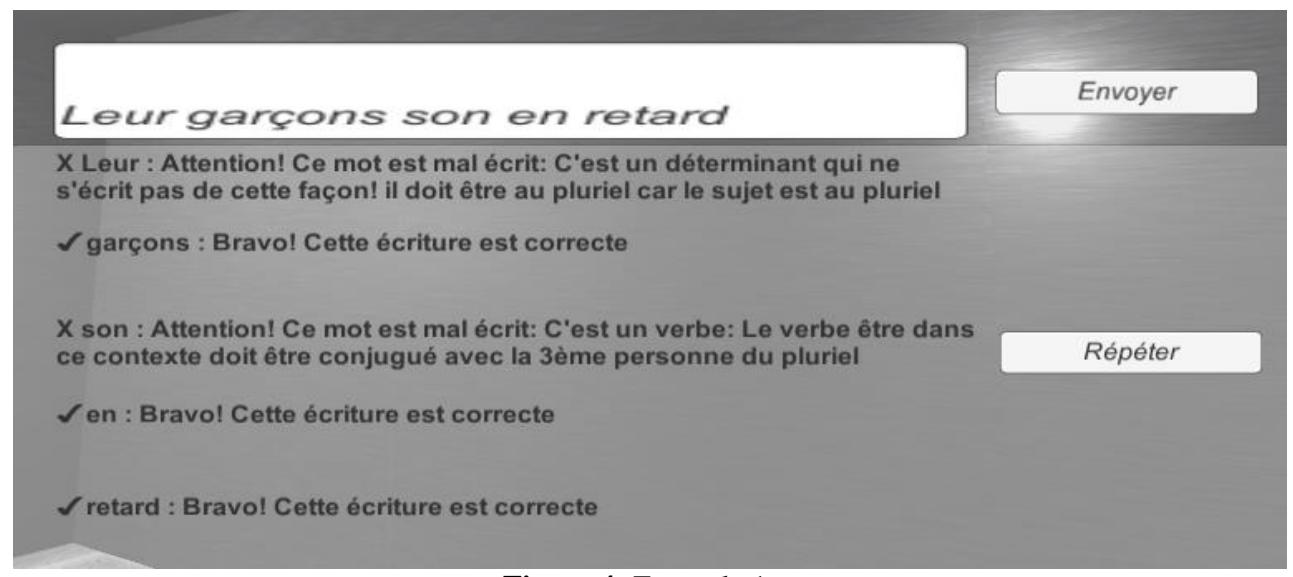

Figure 4: Example 1 


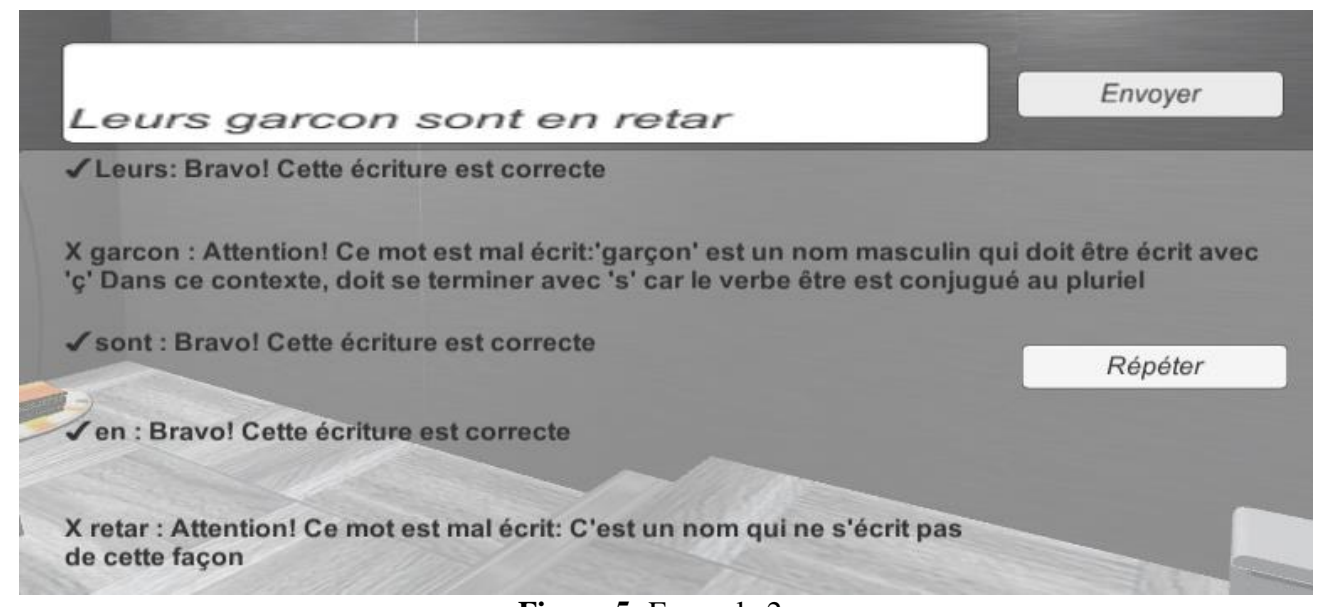

Figure 5: Example 2

\section{Conclusion}

Serious games are powerful educational tools that can achieve pedagogical goals and engage players in deep learning. However, they need strong support from NLP platforms, such as NooJ, in order to be able to perform automatic dictation tasks and correct players' answers. This paper is a proposal for the creation of a connection between NooJ and Unity3D. This connection will open horizons to several future jobs mixing serious games and natural language processing.

\section{References}

Arthur C. Graesser 2016. Reflections on Serious Games. Book chapter from Instructional Techniques to Facilitate Learning and Motivation of Serious Games, pp 199-212.

Clark C. Abt 1970. Serious Games. Viking Press.

Julian Alvarez and Aurélia Rostaing 2014. Autour des jeux sérieux (serious games): Définition générale et terminologie. PowerPoint Presentation. Bibliothèque Nationale de France, Paris. http://www. Iudoscience.com/FR/diffusion/893-Autour-desjeux-serieux-serious-games--Definitiongenerale-et-terminologie.html. Date Accessed: May 12, 2017.
José Simao, Louisa Cotrim, Teresa Condeco, Tiago Cardoso, Miguel Palha, Yves Rybarczyk and José Barata. 2016. Using games for the phonetics awareness for children with Down Syndrome. Serious Games, Interaction and Simulation: 6th International Conference SGAMES 2016 Porto Portugal, (eds. C. Vaz de Carvalho, P. Escudeiro, A. Coelho), Springer International Publishing, pp 1-8

Max Silberztein. 2003. NooJ Manual Available for download at: www. nooj $4 \mathrm{nlp}$. net.

Max Silberztein and Agnès Tutin. 2005. NooJ, un outil TAL pour l'enseignement des langues. Application pour l'étude de la morphologie lexicale en FLE. Special Atala, 8(2), pp 123-134.

Riccardo Berta, Francesco Bellotti, Erik van der Spek and Thomas Winkler. 2016. A Tangible Serious Game Approach to Science, Technology, Engineering, and Mathematics (STEM) Education. Handbook of Digital Games and Entertainment Technologies, pp 571592.

Wim Trooster, Sui Lin Goei, Anouk Ticheloven, Esther Oprins, Gillian van de Boer-Visschedijk, Gemma Corbalan and Martin Van Schaik. 2016. The Effectiveness of the Game LINGO Online: A Serious Game for English Pronunciation. In Simulation and Serious Games for Education, pp 125-136.

Yunus Alyaz, Dorothea Spaniel-Weise and Esim Gursoy. 2017, A Study on Using Serious Games in Teaching German as a Foreign Language. Journal of Education and Learning 6(3), pp 250-264. 